\title{
Comparison between heater with incubator care in providing warmth to low birth weight newborns
}

\author{
Quddush $\mathrm{R}^{1}$, Islam $\mathrm{N}^{2}$, Hasan $\mathrm{MJ}^{3}$, Rahman $\mathrm{M}^{4}$, Rayen $\mathrm{J}^{5}$, Sattar $\mathrm{S}^{6}$
}

\begin{abstract}
Prevention of excessive heat loss is fundamental to survival of low birth weight (LBW) newborns. Highly expensive incubator is not available in most of the health care facilities of Bangladesh. Warm cot care by heater or with light bulbs may alternatively help in maintenance of temperature of LBW newborns in health care facilities where incubator is not available. So far i know no such study was conducted before in our country, this study was carried out to show the effectiveness of warm cot care in comparison to incubator care. The present study was cross sectional descriptive type study conducted in the Department of Neonatology, Mymensingh Medical College over a period 1 year from January 2009 to December 2009. Fifty neonates weighing 1200-2000g with gestational age $\geq 30$ weeks to 40 weeks were allocated to an incubator group and similar number with same criteria were taken as cot care group. In cot care group, those babies were selected that are not supposed to cot care due to lack of incubator. The study showed that there were no differences between infants warm cot care versus incubator care. The temperature of the study patients showed that $34(68.0 \%)$ and $36(72.0 \%)$ maintained normal temperature all the time during hospital stay prior to discharge and rest $16(32.0 \%)$ and $14(28.0 \%)$ in cot and incubator group respectively became either hypothermic or hyperthermic. Mild hypothermia/cold stress was $7(14.0 \%)$ in cot and $4(8.0 \%)$ in incubator group. Moderate hypothermia and severe hypothermia was none in both groups. Hyperthermia/fever was 9(18.0\%) and 10(20.0\%) in cot and incubator group respectively. Analysis reveals that no significant difference was found between two groups. The body temperature of the low birth weight babies (weighing1200-2000g) can be satisfactorily maintained in the low-cost warm cots without the help of incubators which are costly and not available in most of the health care facilities in the developing countries like Bangladesh.
\end{abstract}

Key words: Incubator care, Heater, Low birth weight newborns

\section{Introduction}

Hypothermia in neonates is a common problem and is one of the important causes of morbidity and mortality in neonates particularly in preterm, LBW babies \& about $18-42 \%$ neonatal mortality can be reduced by only preventing hypothermia ${ }^{1}$. There was a case fatality rate of $18.3 \%$ among the hypothermic neonates ${ }^{2}$. Prevention of hypothermia is, therefore, an essential aspect of neonatal care especially in the immediate neonatal period $^{3}$.

Maintenance of body temperature should be high priority when planning for the care of the newborn. This is critically important for preterm and low birth weight (LBW) newborns because of the increased risks of illness and death.Incubator is special equipment for proper maintenance of temperature.It is expensive and not available in most of the health facilities (districts and thana) of Bangladesh.Keeping most LBW newborn babies warm does not require special equipment ${ }^{4}$. Warm cot care may help in maintenance of body temperature with low cost in heath facilities where incubator is not available.

The proportion of babies admitted with normal body temperature $\left(36.5-37.5^{\circ} \mathrm{C}\right)$ was $25.5 \%$. The rest were mildly $\left(36.0-36.5^{\circ} \mathrm{C}\right)(42.2 \%)$ or moderately $\left(<36.0^{\circ} \mathrm{C}\right)$ $(32.2 \%)$ hypothermic. Significantly less normothermia was evident in winter births $(19.6 \%)$ than in summer births $(38.1 \%)^{3}$.
The major causes of neonatal admission in hospital are low birth weight $40.5 \%$, perinatal asphyxia $15.3 \%$, septicemia $15.2 \%$, neonatal jaundice $8.7 \%$ and others $20.2 \%$. Preterm LBW is a major cause of neonatal mortality representing about $29 \%$, septicemia $22 \%$, perinatal asphyxia $16 \%$ and others represents $33 \%$ of neonatal deaths, With the above mentioned scenario, preterm LBW represents a major portion of neonatal morbidity and mortality ${ }^{5}$.

1 * Dr. ASM Ruhul Quddush

Associate Professor, Department of Pediatrics

Community Based Medical College, Bangladesh.

2 Professor Md. Nazrul Islam

Head of the Department of Pediatrics,

Community Based Medical College, Bangladesh.

3 Dr. Mahmud Javed Hasan

Assistant Professor, Department of Nephrology,

Community Based Medical College, Bangladesh

4 Dr. Md. Masudur Rahman

Associate Professor, Department of Radiology \& Imaging

Community Based Medical College, Bangladesh.

5 Dr. Junnu Rayen Janna

Assistant Professor, Department of OBG

Ad-din Women's Medical College.

6 Dr. Shamima Sattar

Lecturer Department of Pharmacology,

Community Based Medical College, Bangladesh

* Address of correspondence:

E-mail: ruhulquddush@gmail.com

Mobile: 0088-01712123225 
Warming devices are convenient for taking care of very small or sick newborns as well as moderately small newborns in cold climate. The advantages of using warming devices include the fact that extra warmth can be given locally instead of having to warm the whole room; temperature control is easier; and newborns can be observed naked when needed.Incubators are the proper choice for the care of very small newborns during the first days or weeks ${ }^{4}$

The cost of an air-heated incubator is high, compared to the relatively cheap alternative of an open cot. If it could be demonstrated that nursing an infant in an open cot instead of an incubator could be achieved without adverse effect, then considerable benefit could accure in economic terms both in developing and developed countries ${ }^{6}$.

However, highly expensive incubator is not available in most of the health facilities of Bangladesh. Warm cot care by heater or with light bulbs may alternatively help in maintenance of temperature of LBW newborns in health care facilities where incubator is not available.So far i know no such study was conducted before in our country, this study was carried out to show the effectiveness of warm cot care in comparison to incubator care.

\section{Methods}

The present study was cross sectional descriptive type study conducted in the Department of Neonatology, Mymensingh Medical College over a period 1 year from January 2009 to December 2009.This studyinvolved neonates admitted to Neonatal unit of Mymensingh Medical College .The mother or guardians were informed of the purpose of the study and their full consent was taken. For each baby a detailed history was taken from mother or the attendant and recorded in a data collection sheet and thorough clinical examination at admission and daily follow up was recorded during the hospital stay. Those babies who fulfill the inclusion criteria(low birth weight weighing $1200-2000 \mathrm{~g}$, gestational age $\geq 30$ weeks, age 0-48 hours)were included for this study

Fifty neonates weighing $1200-2000 \mathrm{~g}$ with gestational age $\geq 30$ weeks to 40 weeks were allocated to an incubator group and similar number with same fulfilling criteria were taken as cot care group.In cot care group, those babies were selected that are not supposed to cot care due to lack of incubator. Infants with gestational age $<30$ weeks, major congenital abnormalities, congenital infections, very sick newborn or those who did not weigh between $1200-2000 \mathrm{~g}$ were excluded from the study. All the babies included in this study were managed according to unit protocol as follows:
The followings were done in the neonates of both groups:

1. Temperature recording-6hourly $(6.00 \mathrm{am}$, 12.00 noon, 6.00 pm, 12.00 night) or more frequently (at least 1 hour) if there was deviation of normal temperature like hypothermia or fever. Axillary or groin temperatures were recorded

2. Weight recording- on daily morning.

3. Vital signs were monitored regularly.

4. Furthermore septic screening, if there was any feature of sepsis. Other complications (NEC, apnea etc.) were observed and managed according to standard protocol.

Routine investigations were done accordingly, all the information were recorded in a questionnaire and subsequently analyzed.

Collected data was checked for its completeness, correctness. Editing and coding were done and then data were entered into computer. Analysis was done by employing Statistical package for Social science (SPSS version 12.0) software Package. Student $t$ test, Chi square test, were performed. P value $<0.05$ was accepted as significant.

\section{Results}

The mean age at admission(hours) was $15.36 \pm 2.49$ and $14.4 \pm 2.65$ in cot and incubator group respectively and the mean gestational age at delivery were $33.08 \pm 4.54$ weeks and $32.6 \pm 4.72$ weeks,weight at admission (gram) was $1541.74 \pm$ 306.43 and $1517.71 \pm 301.57$ respectively in cot and incubator group. The events (maternal diabetes mellitus, fever, toxaemia of pregnancy, antipartumhaemorrhage) of antenatal, natal and postnatal period shows no significant difference in two groups in this study.

The gestational age of the study patients found in cot group $22(44.0 \%)$ in 30-32 weeks of age groups, $23(46.0 \%)$ in 33-35 weeks of age groups, and rest 5 $(10.0 \%)$ in $36-40$ weeks of age groups. Whereas in incubator group $26(52.0 \%)$ was in $30-32$ weeks of age groups. 22(44.0\%) in 33-35 weeks of age groups and rest $2(4.0 \%)$ in $36-40$ weeks of age groups. Analysis reveals that no significant difference was found between two groups (Table I)

The intervention for maintenance of temperature of the cot group patients and found $35(70.0 \%)$ by heater with clothes, $10(20.0 \%)$ by bulbs with clothes above the cot and rest $5(10.0 \%)$ by bulb with clothes from side of the cot.

The temperature of the study patients showed that $34(68.0 \%)$ and $36(72.0 \%)$ maintained normal temperature all the time during hospital stay prior to discharge and rest $16(32.0 \%)$ and $14(28.0 \%)$ in cot and incubator group respectively became either hypothermic or hyperthermic. 
Table I: Distribution of gestational age of the study patients $(n=100)$

\begin{tabular}{|c|c|c|c|c|}
\hline $\begin{array}{c}\text { Gestational } \\
\text { age } \\
\text { (weeks) }\end{array}$ & $\begin{array}{c}\text { Cot(n=50) } \\
\text { Number(\%) }\end{array}$ & $\begin{array}{c}\text { Incubator(n=5 } \\
0)\end{array}$ & Chi value & P value \\
\hline $30-32$ weeks & $22(44.0)$ & $26(52.0)$ & 0.641 & \\
\hline $33-35$ weeks & $23(46.0)$ & $22(44.0)$ & 0.04 & $<0.05$ \\
\hline $36-40$ weeks & $5(10.0)$ & $2(4.0)$ & 1.38 & \\
\hline
\end{tabular}

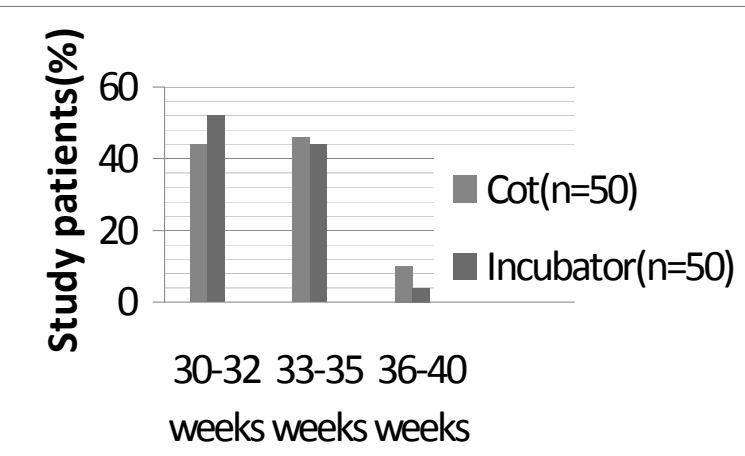

Fig 1: Distribution of gestational age group

Mild hypothermia/cold stress was $7(14.0 \%)$ in cot and $4(8.0 \%)$ in incubator group. Moderate hypothermia and severe hypothermia was none in both groups. Hyperthermia/fever was $9(18.0 \%)$ and $10(20.0 \%)$ in cot and incubator group respectively. Analysis reveals that no significant difference was found between two groups.

Table II: Maintenance of temperature in two groups $(n=100)$

\begin{tabular}{|c|c|c|c|c|}
\hline Temperature & $\begin{array}{l}\text { Cot }(n=50) \\
\text { Number } \\
(\%)\end{array}$ & $\begin{array}{l}\text { Incubator } \\
\text { Number( } \\
\%)\end{array}$ & $\begin{array}{c}\text { Chi } \\
\text { value }\end{array}$ & $\begin{array}{c}\mathrm{p} \\
\text { value }\end{array}$ \\
\hline $\begin{array}{l}\text { Normal } \\
\text { temperature }\end{array}$ & $34(68.0)$ & $36(72.0)$ & & \multirow{6}{*}{$<0.05$} \\
\hline \multicolumn{4}{|l|}{ Hypothermia } & \\
\hline $\begin{array}{l}\text {-mild } \\
\text { hypothermia/ } \\
\text { cold stress }\end{array}$ & $7(14.0)$ & $4(8.0)$ & 0.919 & \\
\hline $\begin{array}{l}\text {-moderate } \\
\text { hypothermia }\end{array}$ & $0(0.0)$ & $0(0.0)$ & & \\
\hline $\begin{array}{l}\text {-severe } \\
\text { hypothermia }\end{array}$ & $0(0.0)$ & $0(0.0)$ & & \\
\hline $\begin{array}{l}\text { Hyperthermia } \\
\text { /fever }\end{array}$ & $9(18.0)$ & $10(20.0)$ & 0.065 & \\
\hline
\end{tabular}

Table III shows the weight association at admission with temperature of the study patients and mainatained normal temperature in $17(34.0 \%)$ and $21(42.0 \%)$ belongs to $1200-1499 \mathrm{~g}$ weight group, 20 $(40.0 \%)$ and $17(34.0 \%)$ belongs to $1500-2000 \mathrm{~g}$ weight group in cot and incubator group respectively. Hypothermia was $2(4.0 \%)$ and $1(2.0 \%)$ belongs to $1200-1499 \mathrm{~g}$ weight group, $1(2.0 \%)$ and none was belongs to $1500-2000 \mathrm{~g}$ weight group in cot and incubator group respectively. Hyperthermia/fever was $6(12.0 \%)$ and $7(14.0 \%)$ belongs to $1200-1499 \mathrm{~g}$ weight group, $4(8.0 \%)$ belongs to $1500-2000 \mathrm{~g}$ weight group in cot and incubator group respectively. Analysis reveals that no significant difference was found between two groups.

Table III: Association of weight at admission with temperature maintenance $(n=100)$

\begin{tabular}{|c|c|c|c|c|c|}
\hline Temperature & $\begin{array}{l}\text { Weight at } \\
\text { Admission(g) }\end{array}$ & $\begin{array}{l}\text { Cot(n=50) } \\
\text { Number(\%) }\end{array}$ & $\begin{array}{l}\text { Incubator }(\mathrm{n}=50) \\
\text { Number }(\%)\end{array}$ & \begin{tabular}{|l} 
Chi \\
value
\end{tabular} & $P$ value \\
\hline \multirow{2}{*}{\begin{tabular}{|l|}
$\begin{array}{l}\text { Normal } \\
\text { temperature }\end{array}$ \\
\end{tabular}} & 1200-1499 & 17 (34.0) & $21(42.0)$ & \multirow[b]{2}{*}{0.053} & \multirow{6}{*}{$<0.05$} \\
\hline & $1500-2000$ & $20(40.0)$ & $17(34.0)$ & & \\
\hline \multirow{2}{*}{\begin{tabular}{|l|} 
Hypothermia/ \\
cold stress
\end{tabular}} & $1200-1499$ & $2(4.0)$ & $1(2.0)$ & \multirow[b]{2}{*}{1.04} & \\
\hline & 1500-2000 & $1(2.0)$ & $0(0.0)$ & & \\
\hline \multirow{2}{*}{$\begin{array}{l}\text { Hyperthermia/ } \\
\text { fever }\end{array}$} & 1200-1499 & $6(12.0)$ & $7(14.0)$ & \multirow{2}{*}{0.06} & \\
\hline & \begin{tabular}{|l}
$1500-2000$ \\
\end{tabular} & $4(8.0)$ & $4(8.0)$ & & \\
\hline
\end{tabular}

Table IV: shows the outcome parameters of the study patients and found mean duration of hospital stay was $11.22 \pm 2.45$ and $11.07 \pm 2.84$ days in cot and incubator group respectively. The mean duration (hrs) of $\mathrm{O}_{2}$ inhalation was in hospital $68.4 \pm 33.66$ hours in cot group and $68.57 \pm 30.73$ hours in incubator group and the mean difference were not statistically significant between two groups, Mortality/death was observed 5(10\%) and 6(12.0\%) in cot and incubator group respectively and the difference was not statistically significant between two groups,

The mean duration (days) to start weight gaining was $11.76 \pm 2.3$ and $11.77 \pm 2.2$ days in cot and incubator group respectively. Though, time (days) to reach full oral feeding in cot group was less (18.1 \pm 3.2 days) than in incubator group (18.18 \pm 3.1 days) Analysis reveals that no significant difference was found between two groups.

Table IV: Outcome between the study groups

\begin{tabular}{|l|l|l|l|l|}
\hline Outcome variables & $\begin{array}{l}\text { Cot } \\
(\mathrm{n}) \mathrm{Mean} \pm \mathrm{SD}\end{array}$ & $\begin{array}{l}\text { Incubator } \\
(\mathrm{n}) \text { Mean } \pm \mathrm{SD}\end{array}$ & value & $\mathrm{p}$ value \\
\hline $\begin{array}{l}\text { Duration (days) of } \\
\text { hospital stay }\end{array}$ & $(45) 11.22 \pm 2.45$ & $(44) 11.07 \pm 2.84$ & $\mathrm{t}=0.26$ & \\
\hline $\begin{array}{l}\text { Duration (hours) of } \mathrm{O}_{2} \\
\text { inhalation in hospital }\end{array}$ & $(12) 68.4 \pm 33.66$ & $(14) 68.57 \pm 30.73$ & $\mathrm{t}=0.13$ & \\
\hline $\begin{array}{l}\text { Duration (days) to start } \\
\text { weight gaining }\end{array}$ & $(45) 11.76 \pm 2.3$ & $(44) 11.77 \pm 2.2$ & & $<0.05$ \\
\hline $\begin{array}{l}\text { Time to reach full oral } \\
\text { feeding }\end{array}$ & $(45) 18.1 \pm 3.2$ & $(44) 18.18 \pm 3.1$ & $\mathrm{t}=0.76$ & \\
\hline Mortality (\%) & $(50) 5(10.0)$ & $(50) 6(12.0)$ & $\mathrm{x}^{2}=0.1 \mathrm{C}$ & \\
\hline
\end{tabular}

The complications of the study patients in two groups among the survivors were sepsis $7(14.7 \%)$ in cot and $9(18.7 \%)$ in incubator group, necrotizing enterocolitis $3(6.4 \%)$ in cot and $4(8.5 \%)$ in incubator groups, apnea $2(4.3 \%)$ in cot and $3(6.4 \%)$ in incubator group and hypoglycemia $1(2.1 \%)$ in cot and similar number 
in incubator groups and no statistically significant difference was seen between two groups.

The association of weight at admission with mortality of the study patients and found that most of the death 3 in cot and 4 in incubator ) occurred in LBW babies weighing $1200-1499 \mathrm{~g}$ and 2 death in incubator group and 2 in cot group were seen in newborns weighing $1500-2000 \mathrm{~g}$. So, the less the weight, the more the mortality and the difference was not statistically significant between two groups.

The association of gestational age with mortality of the study patients were $3(6.0 \%)$ in cot and $4(8.0 \%)$ in incubator group in newborn with $<32$ weeks of gestational age and mortality $2(4.0 \%)$ were observed in $>32$ weeks of gestational age in two groups respectively. So less the gestational age more the mortality.

The association of temperature maintenance with death (mortality) that the variation of body temperature to either cold stress or hyperthermia revealed no correlation with neonatal mortality. Analysis reveals that no significant difference was found between two groups.

\section{Discussion}

This descriptive cross sectional study was done to evaluate the comparative effectiveness between warm cot care and incubator care groups. Total 100 LBW babies weighing 1200-2000 g, aged 0-48 hours and gestational age at delivery 30-40 weeks were observed. They were divided into 2 groups: 50 for warm cot care group and 50 for incubator care group were included. In cot care group, temperature of neonates were managed with extra heating devices like $35(70 \%)$ clothes with heater, $10(20 \%)$ clothes with bulbs from below the cot and $5(10 \%)$ clothes with bulb from sides. Other supportive managements were provided according to the unit protocol. Previous studies also have compared radiant heater and incubators for maintenance of temperatures in the preterm infant 7,8 .

Regarding maintenance of temperature, the result in this study showed no evidence of effect of warm cot care versus incubator care. The study shows there were no differences between infants cot-nursed versus incubator care, with the exception of episodes of high temperature. In more recent years, a heated water-filled mattress (HWM) has been developed to maintain the temperature of a preterm infant who would otherwise be nursed in an air heated incubator ${ }^{9}$.The results of data on mean body temperature were the same as for the overall comparison of cot nursing with heated water filled mattress and incubator care ${ }^{10 .}$

In spite of all our efforts to give breast milk/ breast feeding to all babies, some of them i.e. $7(14 \%)$ in cot and $6(12 \%)$ in incubator groups were given infant formula. Because most of the neonates in this study were admitted in the hospital from out side and their mothers were remaining in hospital/clinic/home. Statistically significant difference was not found between two groups.
The mean duration to start gaining weight, average daily weight gain and time to reach full oral feeding reveals that no significant difference was found between two groups. The trials provided data on weight gain ( $\mathrm{g} / \mathrm{kg}$ body weight/day) sub grouped by week. The results showed no significant differences between the cot-nursing and incubator groups ${ }^{10,11}$. The other study also showed no evidence of effect of cot-nursing versus incubator care on weight gain in the overall analysis, or in the subgroup analysis comparing cot-nursing using a heated water-filled mattress with incubator care ${ }^{12}$

The observed common complications of the study patients were sepsis, NEC and apnea in cot and in incubator groups and the difference was not statistically significant between two groups. Though not statistically significant, sepsis has occurred more in incubator group possibly because of closed environment and inadequate cleaning or sterilization of the incubators. Some of the trials (Green-Abate et al., 1994) has outcomes presented only in a graphical forms and thus, these outcomes could not be included in the meta analysis ${ }^{10}$. The result of the review did not provide reliable evidence that cot nursing is of benefit when compared to incubator care, neither do they suggest that there is increased risk of adverse outcome ${ }^{12}$.

Regarding the other parameters of the study patients prior to hospital discharge, the mean duration of hospital stay was $11.12 \pm 2.45$ and $11.07 \pm 2.84$ days in cot and incubator group respectively. The mean duration (hrs) of $\mathrm{O} 2$ inhalation was $68.4 \pm 33.66$ hours in cot group and $68.57 \pm 30.73$ hours in incubator group and the difference was not statistically significant between the two groups Sarman et al., $(1989 ; 1992)^{11,13}$ in two trials for the outcome of oxygen consumption found neither evidence of effect, nor significant difference between the two groups and also HWM(heated, water-filled mattress ) may constitute a feasible and clinically acceptable alternative in providing warmth to LBW newborns during the neonatal period ${ }^{14}$.

Most of the hospital mortality occurred in both groups (7 of total 11 death) in neonates weighing 1200-1499 $\mathrm{g}$ with gestational age of $<35$ weeks, but revealed no significant difference between two groups. GreenAbate et al (1994) ${ }^{10}$ and Sarman and Tunnell (1989) ${ }^{13}$ also found no significant difference in the outcome of death prior to discharge.

The correlation of temperature maintenance with mortality of the cot group revealed that $3(6 \%)$ death was found in neonates who maintained normal temperature prior to discharge and was diagnosed as sepsis (clinically and CRP- highly raised)but $1(2.0 \%)$ death who faced cold stress / hypothermia and 2 $(4.0 \%)$ who suffered hyperthermia/fever were diagnosed as NEC (clinically and radiologically proved) and sepsis (blood culture-Klebsiella ) respectively. In incubator group, 3(6.0\%) who maintained normal temperature prior to hospital discharge was diagnosed as sepsis (clinically and CRP- highly raised) and $2(4.0 \%)$ who suffered 
hyperthermia/fever were diagnosed,1 (2\%) as IVH (clinically and with USG) and the other (2\%) as NEC (clinically). So, neonatal mortality in this study showed no significant difference was found between two groups.

Above discussion with multiple outcome variables regarding temperature maintenance, weight gain, time to reach full oral feeding, complications, duration of hospital stay, duration of oxygen inhalation and mortality revealed no statistical significant difference between cot care and incubator care groups. So, warm cot care is effective in the maintenance of body temperature of LBW babies in health facilities where incubator in not available.

\section{Conclusion}

The body temperature of the low birth weight babies (weighing1200-2000g) can be satisfactorily maintained in the low-cost warm cots without the help of incubators which are costly and not available in most of the health facilities in the developing countries like Bangladesh.

\section{Reference:}

1. Darmstadt,G.L., Bhutta, Z.A., Cousens, S., Adam, T. Walker, $N$., be Bernis, L. Evidence-based, cost, cost-effective interventions: how many newborn babies can we save? Lncet2005; 365:977-988.

2. Kambarami, R., Chidede, O. Neonatal hypothermia leves and risk factors for mortality in a tropical country. Cent Afr J Med2003;49:103-106.

3. Mizzi, J., Sultana, P. Hythermia in early neonatal period.mdtaMedl J 2003;15:22-24.

4. World Health Organization. Thermal protection of the newborn. A practical Gide, Geneva. World Health Organization1997: 515.

5. Rashid, A.,Ferdous, S., Chowdhury, T., Rahman, F. Morbidity pattern and hospital outcome admitted in tertiary level hospital in Bangladesh. Bangladesh J Child health2003; 27:10-13.

6. Gordon, P.H., Flenady, V. Cot -nursing versus incubator care for preterm infants. Cochrane Neonatal Review2003; 2:1-20.

7. Bell EF, Weinstein MR, Oh $W$ Heat balance in premature infants: comparative effects of convectively heated incubator and radiant warmer, with and without plastic heat shield. J Pediatr 1980; 96:460-465

8. Darnall RA, Ariagno RL Minimal oxygen consumption in infants cared for under overhead radiant warmers compared with conventional incubators. J Pediatr 1978; 93:283-287

9. Tunell $R$, Sarman I. The water-filled heated mattress. An alternative to incubator care in developed and developing countries? In: Rolfe $P$, editor(s). Neonatal Physiological Measurements. London: Butterworths, 1986:419-23.

10. Green-Abate, C., Tafari, N., Rao, M.R., Yu, K.F., Clemens, J.D. Comparison of heated water-filled mattress and spacc-heated room with infant incubator in providing warmth to low birthweight newborns. Int J Epidemiol 1994:23:1226-1233.

11. Sarman, I., Can, G., Tunell .R. Rewarming preterm infants on a by a heated, water filled mattress. Areh Dis ChilHealth1989;27: 687-692.

12. Gray $\mathrm{PH}$, Flenady V. Cot-nursing versus incubator care for preterm infants. Cochrane Database of Systematic Reviews 2001, Issue 2. Art. No.: CD003062. DOI: 10.1002/14651858.CD003062.

13. Sarman I. Thermal responses and heart retes of low-birthweight premature babies during daily care on a heated, waterfilled mattress. Acta Paediatr1992;81:15-20.

14. Nebiattafari, Malla $r$ rao, kai $f$ yuand John $d$ clemens Comparison of Heated Water-Filled Mattress and SpaceHeated Room with Infant Incubator in Providing Warmth to Low Birth weight Newborns Biol Res Nurs, July 1, 2000; 2(1): 60 73 